\title{
Weiterbildung
}

\section{Teilnehmerinnen des Förderprogramms für Dentalhygienikerinnen stehen fest}

Zu Beginn des Jahres rief das Unternehmen Hager \& Werken motivierte Prophylaxefachkräfte auf, sich für eine mit jeweils 2500,- $€$ geförderte Weiterbildung zur Dentalhygienikerin zu bewerben. Zahlreiche Bewerbungen zur Teilnahme am miradent Förderprogramm sind seitdem eingegangen und haben es der Jury nicht leicht gemacht sich für die finalen 10 Kandidatinnen zu entscheiden.

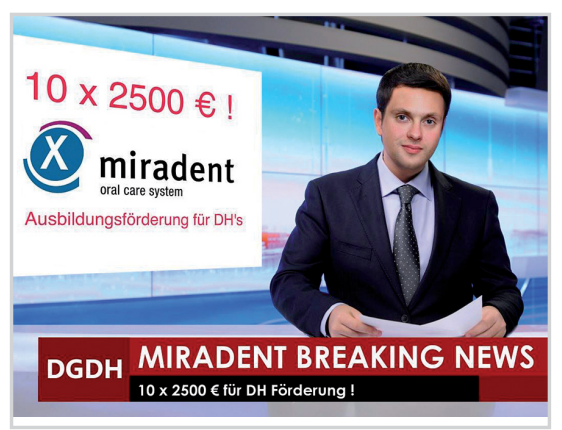

„Unsere Initiative, das Berufsbild der Dentalhygienikerinnen in Deutschland zu fördern und zu stärken ist auf enorm großes Interesse gestoßen“, so Marcus van Dijk, Europaleiter des Dentalherstellers. „Im neuen Jahr werden wir deshalb unser Engagement wiederholen, stellen erneut ein Budget von 25000,- € zur Verfügung und freuen uns ab Januar auf viele weitere Bewerber/innen."Die gesamte Jury bedankt sich für die vielen spannenden Bewerbungen, die mit viel Liebe zum Detail und mit herausfordernden Patientenfällen eingegangen sind. Die glücklichen Gewinnerinnen stehen jetzt fest und werden in den kommenden Tagen benachrichtigt. Wir wünschen den zukünftigen Dentalhygienikerinnen viel Erfolg und Freude im Beruf.

Nach einer Pressemitteilung von Hager \& Werken GmbH \& Co. KG, Duisburg www.hagerwerken.de 